\title{
What is and how to Manage the Acute Respiratory Distress Syndrome?
}

\author{
Claude Guérin ${ }^{*}, 1,2,3$ and Jean-Christophe Richard ${ }^{*}, 1,2,3$ \\ ${ }^{1}$ Service de Réanimation Médicale, Hôpital de la Croix Rousse, Hospices Civils de Lyon, Lyon, France \\ ${ }^{2}$ Université de Lyon, Lyon, France \\ ${ }^{3}$ Creatis, INSERM 630 CNRS 5220, Lyon, France
}

\begin{abstract}
Acute respiratory distress syndrome (ARDS) is an acute hypoxemic respiratory failure with lung oedema of non cardiac origin. Its primary treatment is mechanical ventilation. ARDS is under the spotlights with influenza A pandemic flu. An operating definition has been set out by an experts-consensus conference in order to include patients in clinical trials. However, this definition lacks diagnostic accuracy when compared with lung pathology. The conventional mechanical ventilation has two main objectives: firstly, preservation of arterial blood oxygenation, and secondly, protection of the lung from excessive volume or pressure at the end of inspiration. It has been demonstrated that high tidal volume can increase mortality as compared to low tidal volume. The setting of positive end-expiratory pressure (PEEP) is still not solved. Three large randomized controlled trials failed to demonstrate any benefit between a high and a low level of PEEP. A fascinating strategy of mechanical ventilation is lung recruitment, which is defined as an increase in aerated lung mass by reducing non-aerated or poorly aerated lung mass. Recruiting the lung is useful because it can improve oxygenation and limit ventilator-induced lung injury. Lung recruitment depends not only on the ventilatory settings but also on lung and patient. Several adjunct treatments can be used, as prone position or various pharmacological interventions (inhaled nitric oxide). There are several non conventional methods to deliver mechanical ventilation, such as non invasive mechanical ventilation, liquid ventilation, none of them being recommended to date. Finally, the use of extracorporeal lung support is gaining further interest.
\end{abstract}

Keywords: Acute respiratory distress syndrome, mechanical ventilation, ventilator-induced lung injury, lung protective mechanical ventilation.

\section{INTRODUCTION}

The Acute Respiratory Distress Syndrome (ARDS) has been described more than 40 years ago in US soldiers during the Viet-Nam war [1]. It remains so far a fascinating diseased condition and is still the top medical illness to deal with in the ICU. It is a syndrome, not a disease, with a crude incidence of 78.9 per 100,000 person-years and an ageadjusted incidence of 86.2 per 100,000 person-years in the US [2]. Its mortality remains devastating ranging between 40 to $60 \%$ and remains stable over time [3]. At present time, ARDS is under the spotlight with the pandemic influenza A H1N1 [4]. Besides recognizing and treating aetiology of ARDS, mechanical ventilation is usually required to oppose the very severe hypoxemia that characterizes this condition. Invasive mechanical ventilation is the most common method to deliver respiratory assistance. It has become largely recognized that mechanical ventilation can further damage the lung, leading to the concept of ventilator-induced lung injury (VILI) [5]. The main component of VILI is the overdistension of healthy lung areas due to an excess of endinspiratory lung volume. Indeed, the survival of patients with ARDS has been shown to increase from a reduction in tidal volume and a limitation of end-inspiratory plateau pressure in a large North-American randomized controlled trial [6].

*Address correspondence to these authors at the Service de Réanimation Médicale, Hôpital de la Croix-Rousse, 103 Grande Rue de la Croix Rousse, 69004, Lyon, France; Tel: 334720717 62; Fax: 334720717 74;

E-mails: claude.guerin@chu-lyon.fr, j-christophe.richard@chu-lyon.fr
This special issue aims at focusing on the lung imaging in ARDS. Lung imaging has played a major role to stretch our understanding on the effects of mechanical ventilation in ARDS. The pioneering works of Gattinoni and coworkers by using CT scan raised some fundamental concepts, such as the baby lung and the sponge theory. CT scan raised up the heterogeneity of the lung injury [7]. The CT scan can quantify the amount of recruitment and overdistension in the lungs during mechanical ventilation. Furthermore, lung imaging has the potential to measure lung inflammation, by using PET-scan [8]. Other imaging modalities have the potential to detect at the bedside the amount of recruitment and overdistension.

Before deciphering in great details the lung imaging modalities in this special issue, in the first chapter we will concentrate on the definition and go over the ventilatory management and some adjunct therapies of ARDS.

\section{DEFINITION}

Basically, the ARDS should be defined from pathological changes. The alveolar-capillary membrane can be targeted by direct or indirect insult (Table 1) which increase permeability of the barrier [9]. The endothelial part of the alveolar-capillary membrane is targeted in case of indirect lung injury, as in septic shock. The epithelial part of the barrier is involved in case of pneumonia. After the original injury two consecutive phases evolve. The first, or acute phase, consists of a non hydrostatic, increased-permeability pulmonary oedema with accumulation of fluid into the 
interstitium and the alveolar spaces. This fluid is proteinrich, and contains cells, fibrin, pro-inflammatory and procoagulant molecules. The alveolar space also contains hyaline membranes. Taken together these pathological findings are termed diffuse alveolar damage, which defines the ARDS. At this stage, the lung can completely recover after total fluid resorption and inflammation control or may evolve toward the second phase. This phase is a chronic or fibroproliferative phase. The air spaces are filled with mesenchymal cells [9] and collagen. This alveolar fibrosis frequently does not recover prolonging the stay in the ICU, the duration of invasive mechanical ventilation, the occurrence of ventilator-associated pneumonia and increasing the risk for death. The mechanisms which promote lung repair or non resolution are largely unknown.

Table 1. Causes of Acute Respiratory Distress Syndrome

\begin{tabular}{|c|c|}
\hline Direct Lung Injury & Indirect Lung Injury \\
\hline \hline $\begin{array}{c}\text { Pneumonia (bacteria, virus, } \\
\text { fungi, parasites) }\end{array}$ & Sepsis and septic shock \\
\hline Aspiration of gastric content & Muliple trauma \\
\hline Air or fat emboli & Acute pancreatitis \\
\hline Toxic inhalation & Massive transfusion \\
\hline Near Drowning & Transfusion-related acute lung injury \\
\hline Lung contusion & Drug toxicity \\
\hline $\begin{array}{c}\text { Reperfusion after lung } \\
\text { transplantation or } \\
\text { thrombectomy }\end{array}$ & Neurogenic pulmonary edema \\
\cline { 2 - 2 } & Cardiopulmonary bypass \\
\hline
\end{tabular}

Aggravating common factors: fluid overload, hypervolemia, increased intraabdominal pressure.

The currently accepted definition of ARDS relies on the following four criteria: 1) acute onset of the respiratory failure, 2) new bilateral infiltrates on frontal chest-X-Ray, 3) severe hypoxemia as defined as $\mathrm{PaO}_{2} / \mathrm{F}_{1} \mathrm{O}_{2}$ ratio $\leq 200$ $\mathrm{mmHg}$, where $\mathrm{PaO}_{2}$ is the arterial partial pressure of oxygen and $\mathrm{F}_{\mathrm{I}} \mathrm{O}_{2}$ the inspired fraction of oxygen, and 4) no evidence for an increased left atrial pressure. $\mathrm{PaO}_{2} / \mathrm{F}_{\mathrm{I}} \mathrm{O}_{2}$ ratio $\leq 300$ but greater than $200 \mathrm{mmHg}$ defines acute lung injury (ALI). This is an operating definition stemming from a consensus conference of experts in the field [10]. Operating means that ARDS is suspected from this definition, making the patient at risk for having the ARDS. However, the basic tenets of ARDS, namely increased lung permeability, increased extravascular lung water and lung inflammation, are not specifically identified by this definition. In a series of autopsy, the accuracy of this definition was only moderate [11]. Even though this definition is apparently simple and should allow detection of ARDS on large scale, ARDS was unrecognized in almost $25 \%$ of the cases in the ICU [12]. The lung injury score has been proposed to define ARDS but is less used [13].

\section{VENTILATORY MANAGEMENT OF ARDS}

The mechanical ventilation is the first line therapy in the majority of the ARDS patients due to profound and acute hypoxemia, marked reduction of lung compliance and resulting high work of breathing, and other organs dysfunction [14]. Mechanical ventilation in ARDS has two major objectives, which should be reached simultaneously. The first is to obtain a safe oxygenation. That means that mechanical ventilation should improve oxygenation but also avoid normoxemia. Normal $\mathrm{PaO}_{2}$ is not a target, since it might be obtained by inappropriate and harmful settings, such as high $\mathrm{F}_{\mathrm{I}} \mathrm{O}_{2}$ or high Positive Ned-Expiratory Pressure (PEEP). The current goal is to maintain $\mathrm{PaO}_{2}$ between 55 and $80 \mathrm{mmHg}$. There is no rationale for these thresholds other than the fact that they have been safely used in a very large number of patients [6, 15-18]. As important as preserving safe oxygenation, the other major objective of mechanical ventilation is to protect the lung from VILI. There are several ways to use mechanical ventilation. The conventional mechanical ventilation is to use ICU ventilators in controlled modes, either volume-controlled or pressurecontrolled mode, depending on the expertise of the ICU. Recruitment manoeuvres and adjunct non ventilatory treatments can be added to the conventional mechanical ventilation. The non conventional mechanical ventilation includes non invasive mechanical ventilation, high frequency oscillation ventilation, liquid ventilation, exogenous surfactant administration. Finally, extracorporeal oxygenation and/or $\mathrm{CO}_{2}$ removal techniques can be used in specific settings.

\section{Conventional Mechanical Ventilation}

\section{Volume Controlled Mode}

Volume-controlled mode is the most frequently used ventilatory mode in the ICU worldwide [19]. This is particularly true in ARDS. This mode of ventilation delivers a preset tidal volume in a preset insufflation time at a given respiratory rate. The way to set the ventilator in ARDS has dramatically changed after the demonstration that using low tidal volume in volume controlled mode reduced the absolute mortality by $9 \%$ and the relative mortality by $25 \%$ as compared with high tidal volume [6]. One of the hypotheses subtending these results was reduction of lung and systemic inflammation from the prevention/reduction of overdistension. This study brought several new and key features to standardize the ventilatory settings in the daily practice. The first was to select the tidal volume according to the height and gender of the patients, and hence according an ideal weight predicted by the size. The investigators reasoned that the variables associated with lung volumes are age, gender and mostly height. And so should go the tidal volume. Therefore, the low tidal volumes used [6] was 6 $\mathrm{ml} / \mathrm{kg}$ ideal and not actual body weight and the high tidal volume was $12 \mathrm{ml} / \mathrm{kg}$ ideal body weight. This is now a major recommendation to reduce tidal volume between $4-8 \mathrm{ml} / \mathrm{kg}$ ideal body weight. The plateau pressure, a surrogate of transpulmonary pressure, was monitored in the study and was maintained below $30 \mathrm{~cm} \mathrm{H}_{2} \mathrm{O}$, which was thought a safe threshold to avoid overdistension at the end of inspiration. However, recent studies cast some doubt about the safety of this threshold in any patient since overdistension measured from the CT scan was observed in more than $30 \%$ of the ARDS patients ventilated with a $6 \mathrm{ml} / \mathrm{kg}$ ideal body weight and a plateau pressure below $30 \mathrm{~cm} \mathrm{H}_{2} \mathrm{O}$ [20]. The respiratory rate was increased up to 35 breaths per minute to 
compensate for the lowering of tidal volume and, hence to minimize hypercapnia and respiratory acidosis. The $\mathrm{F}_{\mathrm{I}} \mathrm{O}_{2}$ and PEEP were selected according to a table which provided steps of $\mathrm{F}_{\mathrm{I}} \mathrm{O}_{2}$-PEEP combinations. Average PEEP in both groups was $9 \mathrm{~cm} \mathrm{H}_{2} \mathrm{O}$ [6]. This large scale study validated the concept of VILI from overdistension and changed our practice of mechanical ventilation. However, VILI may also result from a repeated opening and closure of small airways over the respiratory cycles, which can promote lung inflammation [21]. Ventilation at low tidal volumes enhances the risk for this phenomenon to occur. This kind of VILI has been termed low volume barotrauma or atelectrauma and can be minimized by PEEP [22]. Furthermore, the lung inflammation can be exported outside the lungs towards the kidney and the small intestine leading to multiple organ failure [23]. Since PEEP may protect the lung from the atelectrauma, the effect of PEEP on survival in ARDS patients was tested. PEEP was selected from $\mathrm{F}_{\mathrm{I}} \mathrm{O}_{2}$ PEEP tables which were designed to select either high PEEP-low $\mathrm{F}_{\mathrm{I}} \mathrm{O}_{2}$ or low PEEP-high $\mathrm{F}_{\mathrm{I}} \mathrm{O}_{2}$ [17]. Survival was not different between the high PEEP group, $13 \mathrm{~cm} \mathrm{H}_{2} \mathrm{O}$ on average, and low PEEP group, $8 \mathrm{~cm} \mathrm{H}_{2} \mathrm{O}$ on average [17]. Mercat et al. conducted a randomized controlled trial in France over 760 patients with ALI/ARDS testing two levels of PEEP selected on a different background [24]. Whilst tidal volume was set at $6 \mathrm{ml} / \mathrm{kg}$ and plateau pressure maintained below 28-30 $\mathrm{cm} \mathrm{H}_{2} \mathrm{O}$, PEEP was selected according to two strategies. The first was the minimal distension strategy and the second the increased recruitment strategy. The resulting average PEEP was 9 and $14 \mathrm{~cm} \mathrm{H}_{2} \mathrm{O}$ PEEP, respectively. The survival was not different between groups. However, patients in the high PEEP group had higher number of free-ventilatory days. A third study also showed no difference in patient survival between the two groups in which PEEP averaged 10 and $15 \mathrm{~cm} \mathrm{H}_{2} \mathrm{O}$, respectively [25]. In the present time, the issue of setting PEEP is still an open question.

\section{Recruitment Manoeuvres}

Recruiting the lung, that is increasing the aerated lung mass as a result from a reduction of not or poorly aerated lung mass, is a relevant objective of mechanical ventilation in ARDS since it can improve oxygenation and prevent VILI. However, how much recruitment has to be provided with is unknown. Recruitment occurs during tidal breaths. Performing recruitment manoeuvres is a strategy that aims at briefly increasing the plateau pressure above $30 \mathrm{cmH}_{2} \mathrm{O}$ in order to overcome the critical opening pressures of the lung units. There are different methods to recruit the lung, as sighs [26], sustained inflation [27], extended-sighs [28]. After the recruitment manoeuvre, a sufficient amount of PEEP should be set to maintain the recruitment. A full recruitment strategy has been proposed with the goal to increase the airway pressures by steps up to $35 \mathrm{~cm}$ $\mathrm{H}_{2} \mathrm{O}$ of PEEP and $60 \mathrm{~cm} \mathrm{H}_{2} \mathrm{O}$ of plateau pressure over 20 minutes in pressure controlled mode with a constant driving pressure of $15 \mathrm{~cm} \mathrm{H}_{2} \mathrm{O}$ [29]. It must be stressed that the response to the recruitment attempts depends not only on the kind of manoeuvre but also on lung and patient-related factors. Recruitment manoeuvres are currently not recommended in routine but can be applied in case of life-threatening hypoxemia [30].

\section{Adjunct Therapies to the Conventional Mechanical Ventilation}

Several methods can be added to the conventional mechanical ventilation, whose major goal is to improve oxygenation by manipulating the lung ventilation to perfusion ratio. These are inhaled nitric oxide (NOi), prone positioning (PP), and almitrine bismesylate. NOi can improve oxygenation by redirecting blood flow towards well ventilated lung areas and can reduce arterial pulmonary artery pressure, which is frequently high in the ARDS. However, no beneficial effect has been proven on patient outcome and, hence NOi is not recommended in routine in the ARDS [31, 32]. PP is a simple method to improve oxygenation by maintaining the pulmonary blood flow in dorsal regions which become non dependent and better aerated from the proning. A reduction of overdistension has also been observed in ARDS patients with PP [33]. However, no significant benefit has been proven after 4 randomized controlled trials have been completed so far [3437]. Some concerns have been raised about side effects related to the procedure [37]. PP cannot be routinely recommended in ARDS and, should it be applied be reserved to the more hypoxemic patients and performed for more than 12 hours. Almitrine bismesylate redistributes the pulmonary blood flow away the poorly ventilated lung areas [38]. No study has been conducted to test its effect on patient outcome. It cannot be recommended in routine, but could be used in case of life-threatening hypoxemia as recruitment manoeuvres, NOi and PP.

\section{Other Pharmacological Approaches}

\section{Fluid Management}

The increased permeability of the alveolar-capillary membrane enhances the transendothelial fluid rate and, hence the amount of lung oedema if the microvascular pressure is increased or the microvascular colloid osmotic pressure is decreased. This can be obtained by large fluid administration or hypoalbuminemia. As severe sepsis or septic shock is the leading cause of ARDS and large fluid resuscitation is required and recommended in this setting [39], a restrictive fluid administration strategy could be considered in the ARDS, once the circulatory condition is restored. Liberal and restrictive fluid strategies were found not different for survival [15]. The number of ventilatoryfree days and of organ dysfunction were significantly reduced in the restrictive group [15]. Some small size controlled studies suggested that albumin infusion may be beneficial on intermediate physiological end-points [40].

\section{Neuromuscular Blockade}

Intubation and mechanical ventilation in ARDS commonly requires deep sedation in the first hours or days. Adding neuromuscular blockade is controversial since neuromuscular blocking agents (NMBA) were sought to be associated with prolongation of weaning and critical illness 
neuromyopathy, even though the evidence for this is quite low, if any. Use of NMBA and sedation as compared to sedation alone for 48 hours in ARDS patients was associated with better oxygenation [41] and less lung and systemic inflammation [42]. A multicenter randomized control trial recently completed but not yet published as full format showed an increase in survival with the use of NMBA. This effect could be explained by a reduction in lung inflammation and/or a prevention of VILI by limiting the transpulmonary pressure all over the lung in the early stage of ARDS.

\section{Exogenous Surfactant Administration}

Alterations in the metabolism of endogenous surfactant have been repeatedly shown in the ARDS leading to the idea that the exogenous administration of natural or synthetic surfactant may be effective [43]. Extensive research has been done in this area. Several trials administering surfactant either via nebulization [44] or via fiberoptic bronchoscopy [45] have been completed. To date, no study showed any benefit to patient outcome. In the latest trial, there was a trend toward higher mortality in the surfactant group [46].

\section{Steroids}

In the late stage or unresolved ARDS the use of steroids can be considered. However, the data are very conflicting about their net effects and no clear recommendation can be made. The largest trial done so far showed no difference in patient outcome between steroids and placebo and even suggested that steroids may be harmful if started more than 2 weeks after the onset of ARDS [18].

\section{Beta2 Adrenergic Receptors Agonists}

Intravenous beta 2 receptors agonists, which can enhance lung oedema resorption, have been shown to reduce the amount of extravascular lung water as compared to placebo in ARDS [47]. A large scale study is ongoing assessing the effect of this intervention on patient outcome.

\section{Activated C Protein}

Activated C Protein a compound with anti-inflammatory, profibrinolytic and antithrombotic properties has been shown to increase survival in patients with septic shock [48]. In a randomized placebo-controlled trial this molecule demonstrated no significant effect on ventilator-free days in ARDS [49].

\section{Spontaneous Breathing During Conventional Mechanical Ventilation}

Allowing spontaneous breathing during mechanical ventilation is thought to minimize the use of sedation and to help recruiting poorly or not ventilated dorsal lung areas by diaphragmatic contractions [50]. The most studied mode is the Bi Phasic Airway Pressure (BIPAP). In this mode, a high and a low time-cycled level of pressurization are accommodated by the ventilator. At each of these levels, the patient can unrestrictly superimpose her/his own spontaneous breathing. When there is no spontaneous breathing, BIPAP is just a pressure controlled time-cycled mode. Clinical benefit of BIPAP in ARDS has been suggested by small size studies [51, 52], which showed improvement in oxygenation and systemic hemodynamic, and reduction in mechanical ventilation duration and ICU stay. Large scale studies are required.

\section{Non Conventional Mechanical Ventilation}

\section{Non Invasive Mechanical Ventilation}

Non invasive mechanical ventilation (NIV) should be used with caution in case of ARDS and is even not recommended for safety reason [53]. Indeed, between the NIV sessions and, most importantly, in inadvertently facial mask removal the patient is suddenly exposed to ambient air and, hence severe acute hypoxemia may occur with harmful effects [54]. In immuno-compromised patients, however, the use of NIV is beneficial and should be preferred as first line $[55,56]$.

\section{High Frequency Oscillation Ventilation}

High Frequency Oscillation Ventilation (HFO) delivers small tidal volumes at high respiratory rate (up to $15 \mathrm{~Hz}$ ). This lowers the mean lung distending pressure. The addition of small breaths increases the diffusion mechanism of gas exchange. The goal of HFO is to set the tidal breathing in a safety window above substantial recruitment and below overdistension. In controlled trials, HFO failed to demonstrate any benefit to patient outcome [57, 58]. This technique should be reserved in centers which developed expertise with this technique.

\section{Liquid Ventilation}

In Liquid Ventilation, the lungs are filled with oxygenated perfluorocarbon, which is a liquid compound, through the endotracheal tube up to their functional residual capacity. The lungs are also ventilated with gas which is that usually used with conventional mechanical ventilation. The physiological benefits of liquid ventilation come from the followings: oxygen and carbon dioxide transportation along a gradient over the alveolar-capillary membrane, liquid PEEP due to his high specific weight, surfactant-like activity, anti-inflammatory effects. A multicenter phase II trial showed no adverse events associated with perfluorocarbon administration in patients with ARDS. However, there was no benefit to survival [59]. A multicenter phase III trial comparing two regimens of perflubron (10 and $20 \mathrm{ml} / \mathrm{kg}$ body weight) to conventional mechanical ventilation was terminated after an interim analysis performed in 311 patients showed no benefit [60]. The negative results of these two clinical trials marked the end of support for further research in this field [61].

\section{Extracorporeal Oxygenation/ $/ \mathrm{CO}_{2}$ Removal}

Extracorporeal techniques have been used for many years in ARDS. The blood diverted from the body flows through a membrane which provides for pure oxygen and eliminates $\mathrm{CO}_{2}$. Clinical controlled trials failed to demonstrate any clinical benefit [62]. However, recent technical improvement and refinement and recent clinical data make this technique of consideration in the most severe ARDS patients. To date, there are 3 kinds of extracorporeal lung support. The first is the extracorporeal membrane oxygenation (ECMO) in which 
the blood is pumped from a large vein, mostly the inferior vena cava, and flows back to the patient either through a large vein, in general internal jugular vein, or the aorta. The venovenous ECMO is appropriate in the most severely hypoxemic patients, with a $\mathrm{PaO}_{2} / \mathrm{FIO}_{2}$ ratio lower than 50 or $60 \mathrm{~mm} \mathrm{Hg}$ under $\mathrm{F}_{\mathrm{I}} \mathrm{O}_{2} 100 \%$ after having optimized the conventional mechanical ventilation. The venoarterial ECMO is appropriate in case of associated cardiogenic shock due to right or left ventricle failure. The pump can generate a flow rate up to $7 \mathrm{~L} / \mathrm{min}$, depending on the size of the canulations. The second is the pumpless arteriovenous extracorporeal lung support, in which the flow rate is the cardiac output [63]. This technique generates blood flow amounting to $1 \mathrm{~L} / \mathrm{min}$. Finally, low flow (up to $400 \mathrm{ml} / \mathrm{min}$ ) venovenous extracorporeal lung support [64] has recently been implemented in order to maintain plateau pressure below 28 to $30 \mathrm{~cm} \mathrm{H}_{2} \mathrm{O}$ by avoiding severe respiratory acidosis which would result from too low VT. A recent multicenter randomized controlled trail done in the UK compared ECMO performed in a single reference center to conventional mechanical ventilation in patients with acute respiratory failure [65]. This trial showed an improvement in the major end-point, which was survival or no disability at 6 months, in the ECMO group. However, the mortality at 6 months was not statistically significant between groups. Furthermore, some methodological concerns were pointed out: ARDS was not defined according to the consensus definition, making it difficult to compare with other studies, 22 patients allocated to the ECMO group did not receive ECMO, and mechanical ventilatory strategies were not described in both groups. At any rate, ECMO has been used in the recent H1N1 pandemic flu in the western countries. In Canada, ECMO was used in $4.2 \%$ of the 168 adults or children with confirmed or probable 2009 influenza A [66]. In Australia and New Zealand, 68 patients received ECMO and $71 \%$ of them survived [67]. Large scale multicenter randomized controlled trials are mandatory, in which ECMO is performed in the ICU and lung protective mechanical ventilation is applied in the control group.

\section{CONCLUSIONS}

Mechanical ventilation in ARDS is one the hottest challenge the intensivist has to deal with to date. ARDS can be safely managed in the ICU only but it can be aggravated if mechanical ventilation is not appropriately set. To date, the only measure which has been proven to be efficient to patient outcome is the reduction of tidal volume and limitation of the end-inspiratory plateau pressure. The patients who should be involved in the clinical trials testing any of the interventions outlined above or any other intervention whose goal is to improve patient survival are those with the most severe hypoxemia, i.e. $\mathrm{PaO}_{2} / \mathrm{F}_{\mathrm{I}} \mathrm{O}_{2}$ ratio equal to or below $150 \mathrm{mmHg}$, or even lower, with $\mathrm{F}_{\mathrm{I}} \mathrm{O}_{2}$ greater than $50 \%$ and PEEP greater than $5 \mathrm{~cm} \mathrm{H}_{2} \mathrm{O}$.

\section{CONFLICT OF INTEREST}

The authors have no conflict of interest to declare.

\section{REFERENCES}

[1] Ashbaugh DG, Bigelow DB, Petty TL, Levine BE. Acute respiratory distress in adults. Lancet 1967; 2: 319-23.

[2] Rubenfeld GD, Caldwell E, Peabody E, et al. Incidence and outcomes of acute lung injury. N Engl J Med 2005; 353: 1685-93.

[3] Phua J, Badia JR, Adhikari NK, et al. Has mortality from acute respiratory distress syndrome decreased over time?: A systematic review. Am J Respir Crit Care Med 2009; 179: 220-7.

[4] Neumann G, Noda T, Kawaoka Y. Emergence and pandemic potential of swine-origin H1N1 influenza virus. Nature 2009; 459: 931-9.

[5] Dreyfuss D, Saumon G. Ventilator-induced lung injury: lessons from experimental studies. Am J Respir Crit Care Med 1998; 157 : 294-323.

[6] ARDSnet. Ventilation with lower tidal volumes as compared with traditional tidal volumes for acute lung injury and the acute respiratory distress syndrome. The Acute Respiratory Distress Syndrome Network. N Engl J Med 2000; 342: 1301-8.

[7] Gattinoni L, Caironi P, Pelosi P, Goodman LR. What has computed tomography taught us about the acute respiratory distress syndrome? Am J Respir Crit Care Med 2001; 164: 1701-11.

[8] Bellani G, Pesenti A, Guerra A, et al. Imaging of lung inflammation during ALI/ARDS by positron emission tomography (PET): a preliminary report. Intensive Care Med 2007; 33: S 189.

[9] Ware LB, Matthay MA. The acute respiratory distress syndrome. N Engl J Med 2000; 342: 1334-49.

[10] Bernard GR, Artigas A, Brigham KL, et al. Report of the American-European consensus conference on ARDS: definitions, mechanisms, relevant outcomes and clinical trial coordination. The Consensus Committee. Intensive Care Med 1994; 20: 225-32.

[11] Esteban A, Fernandez-Segoviano P, Frutos-Vivar, F et al. Comparison of clinical criteria for the acute respiratory distress syndrome with autopsy findings. Ann Intern Med 2004; 141: 4405.

[12] Ferguson ND, Frutos-Vivar F, Esteban A, et al. Acute respiratory distress syndrome: underrecognition by clinicians and diagnostic accuracy of three clinical definitions. Crit Care Med 2005; 33: 2228-34

[13] Murray JF, Matthay MA, Luce JM, Flick MR. An expanded definition of the adult respiratory distress syndrome. Am Rev Respir Dis 1988; 138: 720-3. 
[14] Tobin MJ. Advances in mechanical ventilation. N Engl J Med 2001; 344: 1986-96.

[15] Wiedemann HP, Wheeler AP, Bernard GR, et al. Comparison of Two Fluid-Management Strategies in Acute Lung Injury. N Engl J Med 2006; 354: 2564-75.

[16] Brower RG, Morris A, MacIntyre N, et al. Effects of recruitment maneuvers in patients with acute lung injury and acute respiratory distress syndrome ventilated with high positive end-expiratory pressure. Crit Care Med 2003; 31: 2592-7.

[17] Brower RG, Lanken PN, MacIntyre N, et al. Higher versus lower positive end-expiratory pressures in patients with the acute respiratory distress syndrome. N Engl J Med 2004; 351: 327-36.

[18] Steinberg KP, Hudson LD, Goodman RB, et al. Efficacy and safety of corticosteroids for persistent acute respiratory distress syndrome. N Engl J Med 2006; 354: 1671-84.

[19] Esteban A, Anzueto A, Alia I, et al. How is mechanical ventilation employed in the intensive care unit? An international utilization review. Am J Respir Crit Care Med 2000; 161: 1450-8.

[20] Terragni PP, Rosboch G, Tealdi A, et al. Tidal hyperinflation during low tidal volume ventilation in acute respiratory distress syndrome. Am J Respir Crit Care Med 2007; 175: 160-6.

[21] Muscedere JG, Mullen JB, Gan K, Slutsky AS. Tidal ventilation at low airway pressures can augment lung injury. Am J Respir Crit Care Med 1994; 149: 1327-34.

[22] Tremblay L, Valenza F, Ribeiro SP, Li J, Slutsky AS. Injurious ventilatory strategies increase cytokines and c-fos m-RNA expression in an isolated rat lung model. J Clin Invest 1997; 99: 944-52.

[23] Slutsky AS, Tremblay LN. Multiple system organ failure. Is mechanical ventilation a contributing factor? Am J Respir Crit Care Med 1998; 157: 1721-5.

[24] Mercat A, Richard JC, Vielle B, et al. Positive end-expiratory pressure setting in adults with acute lung injury and acute respiratory distress syndrome: a randomized controlled trial. JAMA 2008; 299: 646-55.

[25] Meade MO, Cook DJ, Guyatt GH, et al. Ventilation strategy using low tidal volumes, recruitment maneuvers, and high positive endexpiratory pressure for acute lung injury and acute respiratory distress syndrome: a randomized controlled trial. JAMA 2008; 299 : 637-45.

[26] Pelosi P, Cadringher P, Bottino N, et al. Sigh in acute respiratory distress syndrome. Am J Respir Crit Care Med 1999; 159: 872-80.

[27] Lapinsky SE, Aubin M, Mehta S, Boiteau P, Slutsky AS. Safety and efficacy of a sustained inflation for alveolar recruitment in adults with respiratory failure. Intensive Care Med 1999; 25: 1297 301.

[28] Lim CM, Koh Y, Park W, et al. Mechanistic scheme and effect of "extended sigh" as a recruitment maneuver in patients with acute respiratory distress syndrome: a preliminary study. Crit Care Med 2001; 29: 1255-60.

[29] Borges JB, Okamoto VN, Matos GF, et al. Reversibility of lung collapse and hypoxemia in early acute respiratory distress syndrome. Am J Respir Crit Care Med 2006; 174: 268-78.

[30] Fan E, Wilcox ME, Brower RG, et al. Recruitment maneuvers for acute lung injury: a systematic review. Am J Respir Crit Care Med 2008; 178: 1156-63.

[31] Dellinger RP. Inhaled nitric oxide: should it be used in acute respiratory distress syndrome? Crit Care Med 2006; 34: 3035-6.

[32] Adhikari N, Granton JT. Inhaled nitric oxide for acute lung injury: no place for NO? JAMA 2004; 291: 1629-31.

[33] Galiatsou E, Kostanti E, Svarna E, et al. Prone position augments recruitment and prevents alveolar overinflation in acute lung injury. Am J Respir Crit Care Med 2006; 174: 187-97.

[34] Taccone P, Pesenti A, Latini R, et al. Prone positioning in patients with moderate and severe acute respiratory distress syndrome: a randomized controlled trial. JAMA 2009; 302: 1977-84.

[35] Gattinoni L, Tognoni G, Pesenti A, et al. Effect of prone positioning on the survival of patients with acute respiratory failure. N Engl J Med 2001; 345: 568-73.

[36] Mancebo J, Fernandez R, Blanch L, et al. A multicenter trial of prolonged prone ventilation in severe acute respiratory distress syndrome. Am J Respir Crit Care Med 2006; 173: 1233-9.

[37] Guerin C, Gaillard S, Lemasson S, et al. Effects of systematic prone positioning in hypoxemic acute respiratory failure: a randomized controlled trial. JAMA 2004; 292: 2379-87.
[38] Leeman M, Delcroix M, Vachiery JL, Melot C, Naeije R. Almitrine and doxapram in experimental lung injury. Am Rev Respir Dis 1992; 145: 1042-6.

[39] Dellinger RP, Levy MM, Carlet JM, et al. Surviving Sepsis Campaign: international guidelines for management of severe sepsis and septic shock. Crit Care Med 2008; 36: 296-327.

[40] Martin GS, Mangialardi RJ, Wheeler AP, Dupont WD, Morris JA, Bernard GR. Albumin and furosemide therapy in hypoproteinemic patients with acute lung injury. Crit Care Med 2002; 30: 2175-82.

[41] Gainnier M, Roch A, Forel JM, et al. Effect of neuromuscular blocking agents on gas exchange in patients presenting with acute respiratory distress syndrome. Crit Care Med 2004; 32: 113-9.

[42] Forel JM, Roch A, Marin V, et al. Neuromuscular blocking agents decrease inflammatory response in patients presenting with acute respiratory distress syndrome. Crit Care Med 2006; 34: 2749-57.

[43] Spragg RG, Richman P, Gilliard N, Merritt TA, Robertson B, Curstedt $\mathrm{T}$. The use of exogenous surfactant to treat patients with acute high-permeability lung edema. Prog Clin Biol Res 1989; 308: 791-6.

[44] Anzueto A, Baughman RP, Guntupalli KK, et al. Aerosolized surfactant in adults with sepsis-induced acute respiratory distress syndrome. Exosurf Acute Respiratory Distress Syndrome Sepsis Study Group. N Engl J Med 1996; 334: 1417-21.

[45] Spragg RG, Lewis JF, Walmrath HD, et al. Effect of recombinant surfactant protein $\mathrm{C}$-based surfactant on the acute respiratory distress syndrome. N Engl J Med 2004; 351: 884-92.

[46] Kesecioglu J, Beale R, Stewart TE, et al. Exogenous natural surfactant for treatment of acute lung injury and the acute respiratory distress syndrome. Am J Respir Crit Care Med 2009; 180: 989-94.

[47] Perkins GD, McAuley DF, Thickett DR, Gao F. The beta-agonist lung injury trial (BALTI): a randomized placebo-controlled clinical trial. Am J Respir Crit Care Med 2006; 173: 281-7.

[48] Bernard GR, Vincent JL, Laterre PF, et al. Efficacy and safety of recombinant human activated protein $\mathrm{C}$ for severe sepsis. $\mathrm{N}$ Engl J Med 2001; 344: 699-709.

[49] Liu KD, Levitt J, Zhuo H, et al. Randomized clinical trial of activated protein $\mathrm{c}$ for the treatment of acute lung injury. Am J Respir Crit Care Med 2008; 178: 618-23.

[50] Putensen C, Hering R, Muders T, Wrigge H. Assisted breathing is better in acute respiratory failure. Curr Opin Crit Care 2005; 11: 63-8

[51] Putensen C, Mutz NJ, Putensen-Himmer G, Zinserling J. Spontaneous breathing during ventilatory support improves ventilation-perfusion distributions in patients with acute respiratory distress syndrome. Am J Respir Crit Care Med 1999; 159: 1241-8.

[52] Putensen C, Zech S, Wrigge $\mathrm{H}$, et al. Long-term effects of spontaneous breathing during ventilatory support in patients with acute lung injury. Am J Respir Crit Care Med 2001; 164: 43-9.

[53] Boles JM, Bion J, Connors A, et al. Weaning from mechanical ventilation. Eur Respir J 2007; 29: 1033-56.

[54] Delclaux C, L'Her E, Alberti C, et al. Treatment of acute hypoxemic nonhypercapnic respiratory insufficiency with continuous positive airway pressure delivered by a face mask: A randomized controlled trial. JAMA 2000; 284: 2352-60.

[55] Hilbert G, Gruson D, Vargas F, et al. Noninvasive continuous positive airway pressure in neutropenic patients with acute respiratory failure requiring intensive care unit admission. Crit Care Med 2000; 28: 3185-90.

[56] Hilbert G, Gruson D, Vargas F, et al. Noninvasive ventilation in immunosuppressed patients with pulmonary infiltrates, fever, and acute respiratory failure. N Engl J Med 2001; 344: 481-7.

[57] Derdak S, Mehta S, Stewart TE, et al. High-frequency oscillatory ventilation for acute respiratory distress syndrome in adults: a randomized, controlled trial. Am J Respir Crit Care Med 2002; 166: 801-8.

[58] Mehta S, Lapinsky SE, Hallett DC, et al. Prospective trial of highfrequency oscillation in adults with acute respiratory distress syndrome. Crit Care Med 2001; 29: 1360-9.

[59] Hirschl RB, Conrad S, Kaiser R, et al. Partial liquid ventilation in adult patients with ARDS: a multicenter phase I-II trial. Adult PLV Study Group. Ann Surg 1998; 228: 692-700.

[60] Meinhardt JP, Quintel M. In: Papadakos PJ, Lachmann B, Eds. Philadelphia, USA: Saunders Elsevier 2008; pp. 286-96. 
[61] Degraeuwe PL, Zimmermann LJ. Why partial liquid ventilation did not fulfill its promise. Am J Respir Crit Care Med 2006; 174: 615; author reply 615-6.

[62] Morris AH, Wallace CJ, Menlove RL, et al. Randomized clinical trial of pressure-controlled inverse ratio ventilation and extracorporeal $\mathrm{CO}_{2}$ removal for adult respiratory distress syndrome. Am J Respir Crit Care Med 1994; 149: 295-305.

[63] Zimmermann M, Bein T, Arlt M, et al. Pumpless extracorporeal interventional lung assist in patients with acute respiratory distress syndrome: a prospective pilot study. Crit Care 2009; 13: R10.

[64] Terragni PP, Del Sorbo L, Mascia L, et al. Tidal volume lower than $6 \mathrm{ml} / \mathrm{kg}$ enhances lung protection: role of extracorporeal carbon dioxide removal. Anesthesiology 2009; 111: 699-700.
[65] Peek GJ, Mugford M, Tiruvoipati R, et al. Efficacy and economic assessment of conventional ventilatory support versus extracorporeal membrane oxygenation for severe adult respiratory failure (CESAR): a multicentre randomised controlled trial. Lancet 2009; 374: 1351-63.

[66] Kumar A, Zarychanski R, Pinto R, et al. Critically ill patients with 2009 influenza A(H1N1) infection in Canada. JAMA 2009; 302: 1872-9.

[67] Davies A, Jones D, Bailey M, et al. Extracorporeal Membrane Oxygenation for 2009 Influenza A(H1N1) Acute Respiratory Distress Syndrome. JAMA 2009; 302: 1888-95.

(c) Guérin and Richard; Licensee Bentham Open.

This is an open access article licensed under the terms of the Creative Commons Attribution Non-Commercial License (http: //creativecommons.org/licenses/by-nc/ $3.0 /$ ) which permits unrestricted, non-commercial use, distribution and reproduction in any medium, provided the work is properly cited 